\title{
Anti-Depressant Effects of Palmitic Acid: The Necessity of Focusing on New Agents
}

\author{
Alireza Ranaei ${ }^{1}$, Shahriar Najafizadeh-Sari ${ }^{1, *}$ \\ ${ }^{1}$ Student Research Committee, Baqiyatallah University of Medical Sciences, Tehran, Iran
}

Corresponding Author: Shahriar Najafizadeh-Sari, MD, Student Research Committee, Baqiyatallah University of Medical Sciences, Tehran, Iran. E-mail: dr.najafi73@yahoo.com

Received November 3, 2017; Accepted November 22, 2017; Online Published December 25, 2017

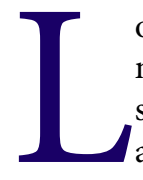
oss of interest in usual activities, dysphoric mood, and other psychiatric signs and symptoms are defined as depression, which has a strong association with many diseases and increases mortality rates. Major Depressive Disorder (MDD) is a common psychiatric disorder. ${ }^{1,2}$ The prevalence of MDD has been determined to be $15 \%-25 \%$. Recent epidemiologic studies have indicated that depression and its side effects are increasing in different societies. ${ }^{3,} 4$ Drugs commonly prescribed for the management of depression include: tricyclic antidepressants (TCAs), selective serotonin reuptake inhibitors (SSRI), and monoamine oxidase enzyme inhibitors (MAOI). Many new drugs have recently been approved, such as Nefazodone and Bupropion. All available synthetic drugs may result in serious complications and fatal side effects. For example, Fluoxetine is an antidepressant of the SSRIs group which acts by increasing the concentration of serotonin in the synaptic cleft. It causes many side effects in patients, such as sexual dysfunction, erectile dysfunction, and inability to have an orgasm. Suddenly discontinuing Fluvoxamine, a common occurrence in psychiatric patients, may result in Fluvoxamine withdrawal syndrome. ${ }^{4}$ Thus, more cost-effective drugs with fewer complications should be considered. Herbal medicine has recently been under consideration. Palmitic and hexadecanoic acids are a type of saturated fatty acid that has antioxidant effects, like other agents such as vitamin D. Low concentrations of palmitic acid occur naturally in plant oil and animal products. ${ }^{5-7}$

In recent years, inflammation and oxidative stress in relation to the interactions between fatty acids (FA) and depression $^{8}$ have been considered. The level of depression has a significant association with serum palmitic acid. Also, using saturated fatty acids increases significantly the combination of saturated fatty acid with serotonergic system receptors. ${ }^{9}$ High fat diets cause important changes in synaptic transmission by increasing glutamate reuptake, causing synaptic effects to subside, and inhibiting mechanisms such as long-term depression in the brain. ${ }^{10}$ Recently, the use of palmitate in the treatment of schizophrenia has received FDA approval. ${ }^{11}$ The composition of palmitic acid, which is called palmitoyl ethanolamide, in combination with luteolin has been shown to have significant antidepressant effects in mice. ${ }^{12}$ Studies have suggested that antioxidant drugs play a role similar to that of antidepressants. ${ }^{13}$ With this background and due to the lack of research on the effects of palmitic acid and its mechanism of acting, it is suggested that researchers consider the effects of palmitic acid as an anti-depressant first on animal models and then on human models.

\section{Acknowledgments}

The authors wish to thank the Baqiyatallah Student Research Committee for their financial support of this study.

\section{Authors' Contributions}

$\mathrm{AR}$ and SNS contributed equally to this research.

\section{References}

1. Sadock B, Sadock V. Mood disorders. In: Blazer D, editor. Kaplan \& Sadock comprehensive textbook of psychiatry. 7th2000. p. 1298-30.

2. Kaplan H, Sadock B, Grebb T. Synopsis of psychiatry. 8th. Maryland: Lippincott Williams \& Wilkins; 1998.

3. Brunton LL, Chabner B, Knollmann BC. Goodman \& Gilman's the pharmacological basis of therapeutics: McGraw Hill companies; 2011.

4. Abraham SK. Anti-genotoxicity of trans-anethole and eugenol in mice. Food Chem Toxicol. 2001;39(5):493-8. pmid: 11313116.

5. Cavalcanti JM, Leal-Cardoso JH, Diniz LR, Portella VG, Costa CO, Linard CF, et al. The essential oil of Croton zehntneri and trans-anethole improves cutaneous wound

Copyright $(02017$ The Author(s). This is an open-access article distributed under the terms of the Creative Commons Attribution License (http://creativecommons.org/licenses/by/4.0), which permits unrestricted use, distribution, and reproduction in any medium, provided the original work is properly cited. 
healing. J Ethnopharmacol. 2012;144(2):240-7. doi: 10.1016/j.jep.2012.08.030. pmid: 23000167.

6. Gunstone FD, Harwood JL, Dijkstra AJ. The lipid handbook with CD-ROM: CRC press; 2007.

7. Najafizadeh-Sari S, Khosravi MH. Vitamin D and viral hepatitis: the new issue in $\equiv$ ggenesis and outcomes. Int J Med Rev. 2017;3(3):457-68

8. Tsuboi H, Watanabe M, Kobayashi F, Kimura K, Kinae N. Associations of depressive symptoms with serum proportions of palmitic and arachidonic acids, and alpha-tocopherol effects among male population--a preliminary study. Clin Nutr. 2013;32(2):289-93. doi: 10.1016/j.clnu.2012 .07.011. pmid: 22901744.

9. Banerjee P, Dawson G, Dasgupta A. Enrichment of saturated fatty acid containing phospholipids in sheep brain serotonin receptor preparations: use of microwave irradiation for rapid transesterification of phospholipids. $\equiv$ im Biop $\equiv$ cta. 1992;1110(1):65-74. doi: Dói 10.1016/00052736(92)90295-W. pmid: 1390837.

10. Contreras A, Del Rio D, Martinez A, Gil C, Morales L, Ruiz-
Gayo $M$, et al. Inhibition of hippocampal long-term potentiation by high-fat diets: is it related to an effect of palmitic acid involving glycogen synthase kinase-3? Neuroreport. 2017;28(6):354-9. doi: 10.1097/WNR.0000000000 000774. pmid: 28328738.

11. Gopal S, Gassmann-Mayer C, Palumbo J, Samtani MN, Shiwach R, Alphs L. Practical guidance for dosing and switching paliperidone palmitate treatment in patients with schizophrenia. Curr Med Res Opin. 2010;26(2):377-87. doi: 10.1185/03007 990903482772. pmid: 20001492.

12. Crupi R, Paterniti I, Ahmad A, Campolo M, Esposito E, Cuzzocrea S. Effects of palmitoylethanolamide and luteolin in an animal model of anxiety/depression. CNS Neurol Disord Drug Targets. 2013;12(7):989-1001. pmid: 23844686.

13. Scapagnini G, Davinelli S, Drago F, De Lorenzo A, Oriani G. Antioxidants as antidepressants: fact or fiction? CNS Drugs. 2012;26(6):477-90. doi: 10.2165/11633190-00000 0000-00000. pmid: 22668245.

Citation: Ranaei A, Najafizadeh-Sari S. Anti-depressant effects of palmitic acid: The necessity of focusing on new agents. Int J Med Rev. 2017;4(4):93-94. doi: 10.29252/ijmr-040401. 